Short Communication

\title{
Whole genome SNPs discovery in Nero Siciliano pig
}

\author{
Enrico D’Alessandro ${ }^{1}$ iD, Domenico Giosa ${ }^{2}$ (D), Irene Sapienza ${ }^{1}$, Letterio Giuffrè ${ }^{1}$ (D), Riccardo Aiese \\ Cigliano $^{3}$, Orazio Romeo ${ }^{2,4}$ (iD and Alessandro Zumbo ${ }^{1}$ (D) \\ ${ }^{I}$ Department of Veterinary Sciences, Division of Animal Production, University of Messina, Messina, Italy. \\ ${ }^{2}$ Department of Chemical, Biological, Pharmaceutical and Environmental Sciences, University of Messina, \\ Messina, Italy. \\ ${ }^{3}$ Sequentia Biotech SL, Barcelona, Spain. \\ ${ }^{4}$ Scientific Institute for Research, Hospitalization and Health Care (IRCCS) - Centro Neurolesi \\ “Bonino-Pulejo”, Messina, Italy.
}

\begin{abstract}
Autochthonous pig breeds represent an important genetic reserve to be utilized mainly for the production of typical products. To explore its genetic variability, here we present for the first time whole genome sequencing data and SNPs discovered in a male domestic Nero Siciliano pig compared to the last pig reference genome Sus scrofa11.1.A total of 346.8 million paired reads were generated by sequencing. After quality control, $99.03 \%$ of the reads were mapped to the reference genome, and over 11 million variants were detected.Additionally, we evaluated sequence diversity in 21 fitness-related loci selected based on their biological function and/or their proximity to relevant QTLs. We focused on genes that have been related to environmental adaptation and reproductive traits in previous studies regarding local breeds. A total of 6,747 variants were identified resulting in a rate of 1 variant every 276 bases. Among these variants 1,132 were novel to the dbSNP151 database. This study represents a first step in the genetic characterization of Nero Siciliano pig and also provides a platform for future comparative studies between this and other swine breeds.
\end{abstract}

Keywords: Nero Siciliano pig, whole genome sequencing, variant calling, SNPs discovery, fitness genes.

Received: June 6, 2018; Accepted: January 4, 2019.

Preservation of genetic variability, used or potentially usable for food production, of non-food raw materials or related to social, cultural, and economic aspects, represents a challenge of fundamental importance on a planetary level. Although the difficulty of conserving biodiversity in species of zootechnical interest is not a recent concern, in recent years the need to preserve genetic variability within breeds has increased and is important in production systems (Kuec et al., 2012). Animal genetic resources and their management systems are an integral part of ecosystems and productive landscapes in Italy, especially in Sicily. The role of livestock is more than ever, to provide sufficient food for humans that is protein-rich, safe and healthy, and with high nutritional and organoleptic values. Local pig breeds can be used for the production of raw materials particularly suitable for production of typical processed products. The higher economic value of typical productions compared to conventional commercial prod-

Send correspondence to Enrico D'Alessandro. Department of Veterinary Sciences, Division of Animal Production, University of Messina. Polo Universitario dell'Annunziata, 98168 Messina, Italy. E-mail: edalessandro@unime.it ucts and the growing consumer preference towards quality food could give support to plans for livestock biodiversity conservation (Herrero-Medrano et al., 2013; Wilkinson et al., 2013). In this respect, governments, institutional breeding organizations, private breeders and market demand play a crucial role in this endeavor toprotect and valuation of local breeds (Tapio et al., 2006; Ollivier, 2009).

Although the interest in local pig breeds has increased significantly in recent years, only a few of them have been included in whole-genome sequencing projects (EsteveCodina et al., 2011, 2013; Herrero-Medrano et al., 2014). The knowledge of the genetic background of these local breeds is very important as many of them have unique characteristics that could help address the challenges related to climate change, increase in world population and for food security and nutrition, as highlighted in the Domestic Animal Diversity Information System (DAD-IS) of FAO.

The Nero Siciliano pig is an autochthonous genetic type of the rural areas in Sicily (Italy). It lives in the woods of the Nebrodi and Madonie mountains and is reared in extensive and semi-extensive systems, making good use of pasture and other natural plant resources following the traditional practices used in this area. It is resistant to disease 
and with a great potential for adaptation to difficult environments, as it has a great ability for rooting and for procuring food. Its "Register of Native Breeds" was established in 2001 and now contains about 14.000 animals, of which $\sim 5.000$ are sows (ANAS - Italian Pig Breeders Association, 2018), from over 128 farms. The meat obtained from these pigs is sold at a higher price than that of commercial pigs, and in 2005 a request was made to allow labelling fresh Nero Siciliano meat with the Protected Denomination of Origin (D'Alessandro et al., 2007). Black pigs are rustic, disease resistant animals, and live well in harsh conditions, but run a high risk of losing their original traits because of the lack of a real plan for genetic selection and setting up appropriate breeding systems and controls. The genetic variability of the Nero Siciliano pig has been assessed with the use of various genetic markers in several studies on molecular characterization of genetic structure and analysis of coat colour genes (MC1R and KIT gene) to evaluate their usefulness for breed traceability (Russo et al., 2004; Fontanesi et al., 2010; Guastella et al., 2010).

All the procedures used in this research were in compliance with the European guidelines for the care and use of animals in research (Directive 2010/63/EU). A blood sample from a male of Nero Siciliano pig was used for DNA extraction. The individual was chosen for this study as one of the most representative boars of this breed, registered in the "Register of native breed" (ANAS; ID:163347). The leukocytes fraction recovered from the fresh whole blood sample was used for total genomic DNA (gDNA) extraction using the Wizard ${ }^{\circledR}$ Genomic DNA Purification Kit (Promega Corporation, Italy), following the manufacturer's instructions. For DNA quantification a Qubit 2.0 Fluorometer was used with the Qubit dsDNA HS Assay Kit (Thermo Fisher, Italy). DNA quality was assessed by a Nanophotometer P-330 (Implen $\mathrm{GmbH}$ ) and also by visual inspection after agarose gel electrophoresis (1\% agarose in TAE $1 \mathrm{X}$ buffer). A PCR-Free library was prepared with TruSeq DNA kit (insert size $350 \mathrm{bp}$ ) using $1 \mu \mathrm{g}$ of gDNA and following the protocol provided by Illumina. Paired-sequencing was carried out with a HiSeqX platform (Illumina).

The sequenced raw reads were checked using the FastQC program and cleaned with Trimmomatic v. 0.36 (Bolger et al., 2014) to remove adapters and low-quality sequences (Phred score $<30$ ). Good quality reads were mapped against the Sus scrofa reference genome (version 11.1; GenBank: GCA_000003025.6) with BWA (version 0.7.12-r1039) (Li and Durbin, 2009) and mapping quality was evaluated using Qualimap2 (Okonechnikov et al., 2016). Single nucleotide polymorphisms (SNPs), short insertions and deletions (INDEL), and structural variants (SVs) analyses were performed using SUPERW and PINDEL pipelines (Ye et al., 2009; Sanseverino et al., 2015). The resulting variants were further filtered using the following parameters: QUAL (phred-scaled quality score of called variant) $\geq 30$, DP (number of high-quality bases for called variant) $\geq 10, \mathrm{AD}$ (allele depth) $\geq 10$, removal of all called variants that showed the same genotype of the reference. Putative effects of SNPs were evaluated using SnpEff software v4_3m_core (Cingolani et al., 2012). We further focused on $2 \overline{1}$ fitness-related gene sequences (Table 1) obtained using samtools (Li et al., 2009) and bcftools (Li, 2011).

Subsequently, the resulting high impact effects mutations were aligned and manually inspected with MEGA7 using the reference genomic and relative transcripts sequences retrieved from GenBank, in order to evaluate the putative functional role of the variants on the respective protein sequences. Variants called by SUPERW and PINDEL were compared with bedtools intersect and duplicates were removed from the PINDEL output. In order to detect novel SNPs, snpSift (Cingolani et al., 2012) was utilized against dbSNP151 database (ftp.ncbi.nih.gov/snp/organisms/pig_9823/) and all resulting novel SNPs were manually examined and confirmed.

To explore the genetic resources of this breed, here we present for the first time the whole genome sequencing analysis of a male domestic Nero Siciliano pig, as well as a comparison with the most recent pig reference genome (Sscrofa 11.1) released by the International Swine Genome Sequencing Consortium and improved in annotation and assembly by Warr et al. (2015). In particular, we focused our attention on 21 genes that were selected according to their function and/or their association with specific traits (Table 1). These genes have been chosen because they affect phenotypes related to rusticity, adaptability to poor conditions of management and feeding, and great resistance to diseases, all these representing some of the most distinctive features of autochthonous breeds, especially the Nero Siciliano pig.

In this study, a total of 346.8 million raw paired-reads were produced by Illumina HiSeq $X$ sequencing. After quality filtering and trimming, $\sim 344.3$ million $(99.29 \%)$ high-quality reads were mapped to the $S$. scrofa reference genome, with a mean coverage of $39.5 \mathrm{X}$. A total of $11,253,945$ genetic variants were detected by SUPERW in this study. Of these, $\sim 82 \%$ were SNPs whereas $\sim 12 \%$ and $\sim 5 \%$ were short insertions and deletions respectively. Moreover, more than $58 \%$ of the detected SNPs $(6,555,556$ variants) were heterozygous, while the remaining $42 \%$ were found in alternative homozygosity state. The overall observed frequency was 1 variant every 222 bases, with a SNP mutation rate of 1/269 bp. However, we cannot confirm that all DNA mutations detected in this study segregate in the Nero Siciliano breed, as only one sample was considered.

SnpEff analysis showed that most of the variants recognized were located in non-coding regions of the genome, such as introns and intergenic regions (Figure 1a). Approximately $36 \%$ of the missense, $0.4 \%$ nonsense, and $63,6 \%$ silent mutations were observed, resulting in a missense/silent 
Table 1 - List of 21 fitness related genes investigated in this study. The table shows the chromosome, gene symbol, gene function or putative gene association, starting and ending coordinates, reference.

\begin{tabular}{|c|c|c|c|c|c|}
\hline Chr & Gene symbol & $\begin{array}{l}\text { Gene function or putative association with } \\
\text { QTLs }\end{array}$ & Start & End & Reference \\
\hline 1 & ESR1 & total newborn, newborn alive & 14217032 & 14604906 & Rothschild et al., 1996 \\
\hline 1 & VPS13A & $\begin{array}{l}\text { maintenance of thermostatic status, blood } \\
\text { circulation }\end{array}$ & 230069339 & 230331343 & Groenen, 2016 \\
\hline 1 & NR6A1 & body size & 265320597 & 265570941 & Groenen, 2016 \\
\hline 2 & FSHB & total newborn, newborn alive & 30395769 & 30399282 & Zhao et al., 1998 \\
\hline 3 & EIF2AK3 & $\begin{array}{l}\text { gene overlaps with QTLs for } \\
\text { osteochondrosis score and feet and leg } \\
\text { conformation }\end{array}$ & 57423894 & 57506247 & Laenoi et al., 2011 \\
\hline 3 & AZGP1 & adaptation to environment & 7867521 & 7874857 & $\begin{array}{l}\text { Beeckmann et al., 2003; Ma et al., 2009; } \\
\text { Harmegnies et al., } 2006\end{array}$ \\
\hline 4 & PLAG1 & body size & 75646585 & 75696718 & Rubin et al., 2012 \\
\hline 6 & IL12RB2 & immune related gene & 145210251 & 145292399 & $\begin{array}{l}\text { Koch et al., 2012; Herrero-Medrano et } \\
\text { al., } 2014\end{array}$ \\
\hline 6 & FUT1 & resistance to disease & 54077431 & 54080475 & $\begin{array}{l}\text { Meijerink et al., 1997, 2000; Bao et } \\
\text { al., 2012; Zhang et al., 2015; Fernández et } \\
\text { al., } 2017\end{array}$ \\
\hline 8 & GNRHR & Ovulation rate & 65470206 & 65488900 & Jiang et al., 2001 \\
\hline 8 & LCORL & body size & 12806878 & 12969370 & Rubin et al., 2012 \\
\hline 9 & AHR & litter size & 86511866 & 86555950 & Bosse et al., 2014 \\
\hline 12 & PPP1R1B & candidate genes affecting behaviour & 22681244 & 22690978 & Groenen, 2016 \\
\hline 13 & STAB1 & $\begin{array}{l}\text { immune related gene, defence against bac- } \\
\text { terial infection }\end{array}$ & 34630448 & 34659371 & $\begin{array}{l}\text { Herrero-Medrano et al., 2014; } \\
\text { Kzhyshkowska, } 2010\end{array}$ \\
\hline 13 & GPR149 & potential effect on fertility, prolificacy & 94356371 & 94419917 & Choi et al., 2015 \\
\hline 13 & CLDN1 & potential effect on fertility & 127714857 & 127730628 & Choi et al., 2015 \\
\hline 14 & RBP4 & total newborn, newborn alive & 105037360 & 105044552 & Rothschild et al., 2000 \\
\hline 14 & JMJD1C & potential effect on fertility & 66640845 & 66966911 & Choi et al., 2015 \\
\hline 15 & DCAF17 & $\begin{array}{l}\text { maintenance of thermostatic status, hair } \\
\text { growth }\end{array}$ & 77564629 & 77603913 & Groenen et al., 2016 \\
\hline 16 & PRLR & $\begin{array}{l}\text { involved in several reproductive traits, in- } \\
\text { cluding litter size }\end{array}$ & 20637568 & 20655881 & $\begin{array}{l}\text { Vincent et al., 1998; van Rens et al., 2003; } \\
\text { Tomás et al., } 2006\end{array}$ \\
\hline 18 & TAS2R40 & $\begin{array}{l}\text { adaptation to specific dietary repertoires } \\
\text { and environment }\end{array}$ & 7024418 & 7027197 & $\begin{array}{l}\text { Dong et al., 2009; Fischer et } \\
\text { al., 2005, Ribani et al., } 2017\end{array}$ \\
\hline
\end{tabular}

and Ts/Tv (transition/transversion) ratio of 0.5617 and 2.3956 respectively. However, the Ts/Tv ratio was similar to other pig genomes (Kang et al., 2015), while the observed SNP mutation rate was slightly higher than that reported by Jungerius et al. (2005).

Among the structural variants identified by PINDEL, we observed a total of 808,486 insertions, 452,926 deletions, 196,971 replacements, 2,383 tandem duplications, and 1,029 inversions. Of these, 586,686 were heterozygous, whereas 875,109 were in alternative homozygosity.

Using the panel of fitness-related genes selected in this study, we identified a total of 6,747 SNPs and short INDELs (Figure 1b), that were classified according to Cingolani et al. (2012) in 7 "high", 35 "moderate", 54 "low impact" and 6,651 as modifiers (Table 2). This resulted in a mutation rate of 1 per $\sim 276$ bases; for further details see the supplementary material Tables S1, S2, and S3. Among the total variants identified, 1,132 were novel, consisting of 476 heterozygous and 656 in alternative homozygosity form.

The seven high impact mutations, all in the alternative homozygous state, affected five out of the 21 examined genes: VPS13A (Vacuolar protein sorting 13 homolog A); AZGP1 (Alpha-2-glycoprotein 1, zinc-binding); LCORL (Ligand-dependent nuclear receptor corepressor-like protein), FUT1 (Fucosyltransferases 1); PRLR (Prolactin Receptor). Such variants consisted in one SNP and six nucleotide insertions. Four of these latter were gain of function mutations and restored the reading frames of the VPS13A, AZGP1, FUT1 and PRLR genes, as evidenced by comparative analysis with the reference genome and its transcripts. The remaining two insertions produced a premature stop codon and a lack stop codon in the $A Z G P 1$ and $L C O R L$ genes respectively, whereas the unique SNP de- 


\section{a)}
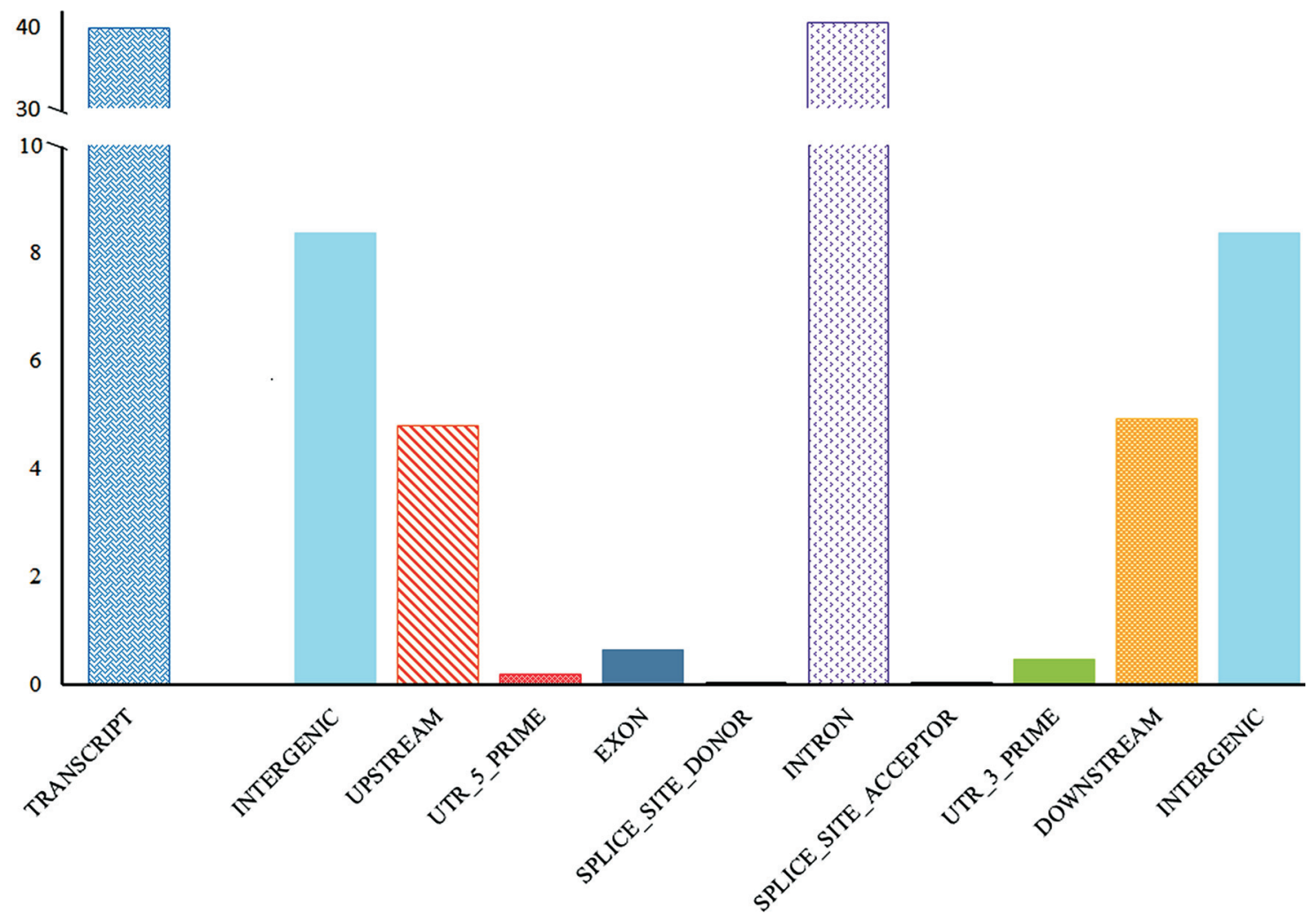

b)

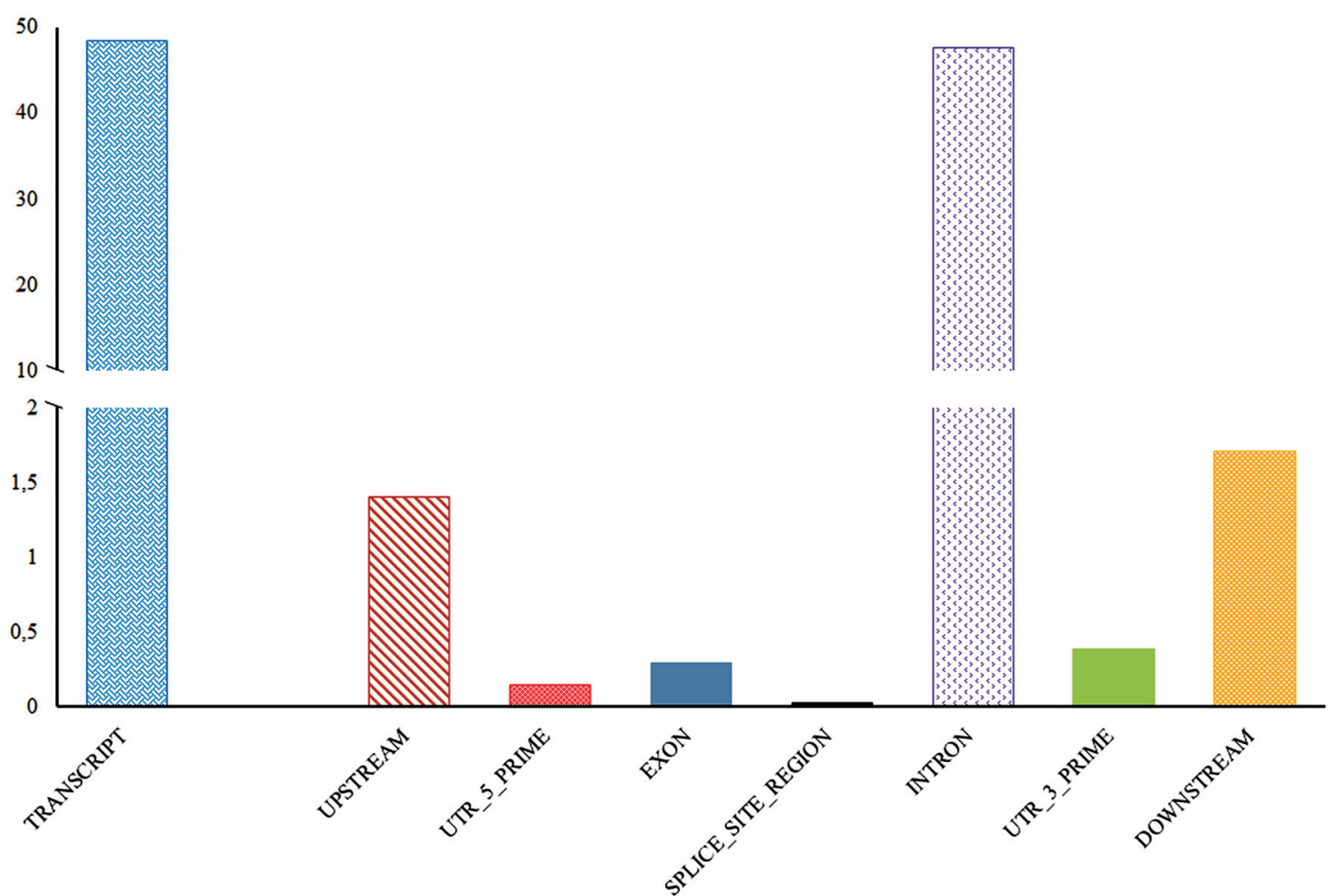

Figure 1 - SNPs and short INDELs detected in this study in (a) whole genome and (b) in fitness related genes, and their location based on genomic annotation. Y-axis, represents the percentage of the variants. 
Table 2 - SNPs, short INDELs, and structural variants detected in the 21 fitness-related genes examined in this study.

\begin{tabular}{|c|c|c|c|c|c|c|c|c|}
\hline \multirow[t]{2}{*}{ Gene symbol } & \multirow[t]{2}{*}{ Length } & \multicolumn{4}{|c|}{ Variants (SNPs and short INDEL) classified by impact } & \multirow[t]{2}{*}{ Total } & \multirow[t]{2}{*}{$\%$ Variants/length } & \multirow{2}{*}{$\begin{array}{c}\text { Structural } \\
\text { variants }\end{array}$} \\
\hline & & High & Low & Moderate & Modifier & & & \\
\hline ESR1 & 387875 & 0 & 14 & 0 & 2891 & 2905 & 0.749 & 102 \\
\hline VPS13A & 262005 & 1 & 1 & 1 & 370 & 373 & 0.142 & 36 \\
\hline NR6A1 & 250345 & 0 & 0 & 1 & 9 & 10 & 0.004 & 13 \\
\hline FSHB & 3514 & 0 & 0 & 0 & 0 & 0 & 0.000 & 0 \\
\hline EIF2AK3 & 82354 & 0 & 1 & 0 & 410 & 411 & 0.499 & 24 \\
\hline AZGP1 & 7337 & 2 & 4 & 7 & 66 & 79 & 1.077 & 2 \\
\hline PLAG1 & 50134 & 0 & 0 & 0 & 3 & 3 & 0.006 & 1 \\
\hline IL12RB2 & 82149 & 0 & 4 & 4 & 318 & 326 & 0.397 & 11 \\
\hline FUT1 & 3045 & 2 & 0 & 0 & 3 & 5 & 0.164 & 1 \\
\hline GNRHR & 18695 & 0 & 0 & 0 & 25 & 25 & 0.134 & 3 \\
\hline LCORL & 162493 & 1 & 4 & 1 & 422 & 428 & 0.263 & 30 \\
\hline AHR & 44085 & 0 & 8 & 9 & 494 & 511 & 1.159 & 20 \\
\hline PPP1R1B & 9735 & 0 & 0 & 0 & 13 & 13 & 0.134 & 2 \\
\hline STAB1 & 28924 & 0 & 1 & 3 & 9 & 13 & 0.045 & 1 \\
\hline GPR149 & 63547 & 0 & 9 & 4 & 370 & 383 & 0.603 & 10 \\
\hline CLDN1 & 15772 & 0 & 0 & 0 & 8 & 8 & 0.051 & 0 \\
\hline RBP4 & 7193 & 0 & 1 & 0 & 56 & 57 & 0.792 & 2 \\
\hline JMJD1C & 326067 & 0 & 5 & 0 & 762 & 767 & 0.235 & 62 \\
\hline DCAF17 & 39285 & 0 & 1 & 2 & 178 & 181 & 0.461 & 10 \\
\hline PRLR & 18314 & 1 & 1 & 3 & 240 & 245 & 1.338 & 15 \\
\hline TAS2R40 & 2780 & 0 & 0 & 0 & 4 & 4 & 0.144 & 0 \\
\hline TOTAL & 1865648 & 7 & 54 & 35 & 6651 & 6747 & 0.362 & 345 \\
\hline
\end{tabular}

SNP, single nucleotide polymorphism; short INDEL, short Insertions and deletions.

tected was a missense mutation (ACGàGCG; $\mathrm{Thr}^{103} \mathrm{àAla}^{103}$ ) affecting the FUT1 gene. Five of these seven high impact mutations were novel to the dbSNP database (see Table S1).

Among the structural variations affecting the subset of the fitness-related genes we observed 101 replacements (RPL), 132 insertions, and 112 deletions. Of these, 203 were heterozygous and 142 were in the alternative homozygosity state. Figure 2 shows the gene-wide distribution of all detected mutations including the related sequencing coverage for all genes investigated.

SNPs discovery analysis of the 21 fitness-related genes showed a coherent rate of mutation compared to the whole genome data. We focused on high impact mutations that may affect the gene product. The VPS13A gene plays a role in maintenance of thermostatic conditions during thermal stress and is involved in blood circulation (Groenen, 2016). We found a novel nucleotide insertion ( $G$, genome position: 230125827) that causes a frameshift mutation restoring the $V P S 13 A$ reading frame.

$A Z G P 1$ is a putative candidate gene for adaptation to environment. A mutation in this gene, that overlaps QTLs for the number of vertebra (Beeckmann et al., 2003; Harmegnies et al., 2006), abdominal fat and ear shape and size
(Ma et al., 2009), was identified in Mangalica, Cinta Senese, and one European wild boar, but not in commercial pigs (Herrero-Medrano et al., 2014). Furthermore, AZGP1 is correlated with lipid mobilization and it is considered a candidate gene for body weight regulation and obesity in humans (Mracek et al., 2010). We found two novel frameshift mutations in this gene, both nucleotide insertions (genome positions: 7874326 and 7874521 of the chromosome 3 ), which could affect its function, with possible effects on fat deposition. The LCORL gene overlaps a QTL involved in morphological modifications occurring during domestication events regarding elongation of the back and an increased number of vertebrae (Rubin et al., 2012). This gene is considered a candidate gene for body size. A known LCORL frameshift mutation (rs791023757; genome position: 12829718) was detected in this study and resulted in a lacking stop codon. Unfortunately, no phenotypes have been associated so far with this mutation, as evidenced by lack of information in the dbSNP database.

We found two variants with high impact also in FUT1 gene. This gene encodes a membrane protein involved in the synthesis of a precursor of blood group antigen. Previous studies showed that polymorphisms in this gene are associated with adhesion and colonization capacity of F18 


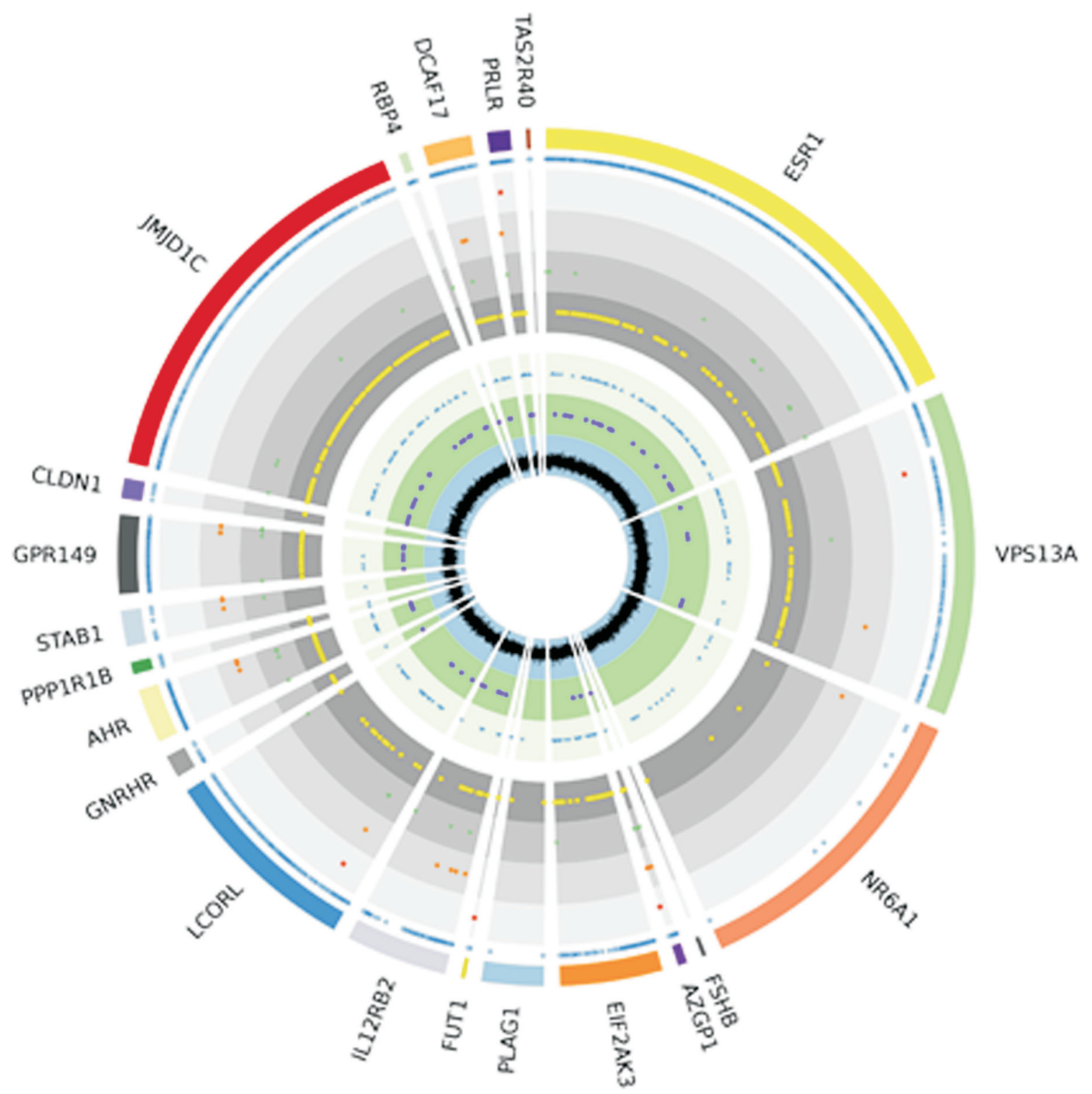

Figure 2 - Variants detected in 21 fitness-related genes. From outside to inside, rings show: all SNPs and INDELs (blue circles), HIGH impact (red square), MODERATE impact (orange circles), LOW impact (green triangles), novel SNPs and short INDELs (yellow circles), SV INDEL (blue triangles), SV RPL (purple circles), reads coverage (black lines).

fimbriated Escherichia coli to intestinal mucosa (Bao et al., 2012; Zhang et al., 2015). The toxins produced by this microrganism cause piglet post-weaning diarrhea (Luo et al., 2010; Zhang et al., 2015). We identified a missense mutation in position 54079560 of chromosome 6 (FUT1 gene) that results in an amino acid change at position 103 (ThràAla) of the protein. This SNP, already recorded in the dbSNP database (rs335979375), was associated with $E$. coli F18-resistant or susceptible genotypes (Meijerink et al., 1997, 2000). Tthe second identified variant was a $\mathrm{G}$ insertion (genome position: 54079637), but further studies will be needed to validate these findings and the role of these mutations in the Nero Siciliano breed.
The PRLR gene encodes a receptor for prolactin and is considered a strong candidate gene for various traits affecting directly (ovulation rate) or indirectly (ovarian weight, uterine length and number of teats) litter size and general reproductive performance in pigs (Vincent et al., 1998; van Rens et al., 2003; Tomás et al., 2006). In the PRLR gene we detected a $G$ insertion in position 20642378 (chromosome 16), but its contribution to the phenotypic variation remains to be elucidated.

The Nero Siciliano pig is not a well-characterised breed, and this study represents a first step in the genetic characterization of this animal, even if further research on the whole population reared in Sicily is needed to confirm 
the observed genetic variation and to integrate our data. In fact, all genetic changes detected in this study are only differences compared to the reference genome used and are therefore not indicative of the presence of mutated loci in the breed.

Since publication of the Sus scrofa reference genome (Warr et al., 2015), several re-sequencing projects have been undertaken, but few have focused on local breeds. In this study we report, for the first time, the sequencing and variant calling analysis of a single boar of Nero Siciliano pig, with the aim of starting to acquire useful information on its genetic background that could be crucial to understand new genetic selection concepts for creating new sustainable pork chains based on local pig breeds. Therefore, the importance of preserving local breeds as a source of genomic diversity for further improvements of commercial pigs represents an added value in typical local productions. However, currently, in Italy the information regarding local pigs is strongly limited and therefore further sequencing studies will be essential for detecting the extent of genetic diversity occurring in Nero Siciliano pig.

The data sets supporting the results of this article are included within the article and its additional files. The raw reads used for the genome-wide analysis have been deposited in the NCBI Sequence Read Archive (SRA) under the following accession number: SRX3406507.

\section{Conflict of interests}

Authors declare there is no conflict of interest

\section{Author contributions}

$\mathrm{ED}$ and $\mathrm{AZ}$ conceived and designed the experiments; IS, LG performed the experiments; DG, RAC, OR carried out bioinformatics analysis; $\mathrm{ED}$ and $\mathrm{AZ}$ interpreted the data and wrote the manuscript; all other authors provided suggestions and comments for the improvement of the paper. All authors read and approved the final manuscript.

\section{References}

Bao WB, Ye L, Zi C, Su XM, Pan Zy, Zhu J, Zhu GQ, Huang XG and $\mathrm{Wu}$ SL (2012) Study on the age-dependent tissue expression of FUT1 gene in porcine and its relationship to $E$. coli $\mathrm{F} 18$ receptor. Gene 497:336-339.

Beeckmann P, Schroffel J, Moser G, Bartenschlager H, Reiner G and Geldermann H (2003) Linkage and QTL mapping for Sus scrofa chromosome 3. J Anim Breed Genet 120:20-27.

Bolger AM, Lohse M and Usadel B (2014) Trimmomatic: A flexible trimmer for Illumina sequence data. Bioinformatics 30:2114-2120.

Bosse M, Megens HJ, Frantz LAF, Madsen O, Larson G, Paudel Y, Duijvensteijn N, Harlizius B, Hagemeijer Y, Crooijmans RP et al. (2014) Genomic analysis reveals selection for Asian genes in European pigs following human-mediated introgression. Nat Comm 5:4392.
Choi JW, Chung WH, Lee KT, Cho ES, Lee SW, Choi BH, Lee SH, Lim W, Lee YG, Hong JK et al. (2015) Whole-genome resequencing analyses of five pig breeds, including Korean wild and native, and three European origin breeds. DNA Res 22:259-267.

Cingolani P, Patel VM, Coon M, Nguyen T, Land SJ, Ruden DM and Lu X (2012) SnpSift. Front Genet 3:35.

D’Alessandro E, Fontanesi L, Liotta L, Davoli R, Chiofalo V and Russo V (2007) Analysis of the MC1R gene in the Nero Siciliano pig breed and usefulness of this locus for breed traceability. Vet Res Commun 31:389-392.

Dong D, Jones G and Zhang S (2009) Dynamic evolution of bitter taste receptor genes in vertebrates. BMC Evol Biol 9:12.

Esteve-Codina A, Kofler R, Himmelbauer H, Ferretti L, Vivancos AP, Groenen MAM, Folch JM, Rodríguez MC and Pérez-Enciso M (2011) Partial short-read sequencing of a highly inbred Iberian pig and genomics inference thereof. Heredity 107:256-264.

Esteve-Codina A, Paudel Y, Ferretti L, Raineri E, Megens HJ, Silio L, Rodrìguez MC, Groenen MA, Ramos-Onsins SE and Pèrez-Enciso M (2013) Dissecting structural and nucleotide genome-wide variation in inbred Iberian pigs. BMC Genomics 14:148.

Fernández AI, Muñoz M, García F, Núñez Y, Geracci C, Crovetti A, García-Casco J, Alves E, Skrlep M, Riquet J et al. (2017) Distribution of polymorphisms in major and candidate genes for productive and domestication-related traits in European local pig breeds. 36th International Society for Animal Genetics Conference, Dublin.

Fischer A, Gilad Y, Man O and Pääbo S (2005) Evolution of bitter taste receptors in humans and apes. Mol Biol Evol 22:432-436.

Fontanesi L, D'Alessandro E, Scotti E, Liotta L, Crovetti A, Chiofalo V and Russo V (2010) Genetic heterogeneity and selection signature at the KIT gene in pigs showing different coat colours and patterns. Anim Genet 41:478-492.

Groenen MAM (2016) A decade of pig genome sequencing: A window on pig domestication and evolution. Genet Sel Evol 48:23.

Guastella AM, Criscione A, Marletta D, Zuccaro A, Chies L and Bordonaro S (2010) Molecular characterization and genetic structure of the Nero Siciliano pig breed. Genet Mol Biol 33:650-656.

Harmegnies N, Davin F, De Smet S, Buys N, Georges M and Coppieters W (2006) Results of a whole-genome quantitative trait locus scan for growth, carcass composition and meat quality in a porcine four-way cross. Anim Genet 37:543-553.

Herrero-Medrano JM, Megens HJ, Crooijmans RP, Abellaneda JM and Ramis G (2013) Farm-by-farm analysis of microsatellite, mtDNA and SNP genotype data reveals inbreeding and crossbreeding as threats to the survival of a native Spanish pig breed. Anim Genet 44:259-266.

Herrero-Medrano JM, Megens HJ, Groenen M, Bosse M, PérezEnciso M and Crooijmans R (2014) Whole-genome sequence analysis reveals differences in population management and selection of European low-input pig breeds. BMC Genomics 15:601.

Jiang Z, Gibson JP, Archibald AL and Haley CS (2001) The porcine gonadotropin-releasing hormone receptor gene (GNRHR): Genomic organization, polymorphisms, and as- 
sociation with the number of corpora lutea. Genome 44:712.

Jungerius BJ, Jingjing G, Crooijmans RPMA, Van Der Poel JJ, Groenen MAM, Van Oost BA and Te Pas MFWl (2005) Estimation of the extent of linkage disequilibrium in seven regions of the porcine genome. Animal Biotechnol 16:41-54.

Kang H, Wang H, Fan Z, Zhao P, Khan A, Yin Z, Wang J, Bao W, Wang A, Zhang Q et al. (2015) Resequencing diverse Chinese indigenous breeds to enrich the map of genomic variations in swine. Genomics 106:286-294.

Koch MA, Thomas KR, Perdue NR, Smigiel KS, Srivastava S and Campbell DJ (2012) T-bet(+) Treg cells undergo abortive Th1 cell differentiation due to impaired expression of IL-12 receptor $\beta 2$. Immunity 37:501-510.

Kuec G, Dovc P, Karloy D and ĖandekPotokar M (2012) Local pig breeds and pork products in Croatia and Slovenia - Unexploited treasure. Poljopriveda 21:16-21.

Kzhyshkowska J (2010) Multifunctional receptor stabilin-1 in homeostasis and disease. Sci World J 10:2039-2053.

Laenoi W, Uddin MJ, Cinar MU, Grosse-Brinkhaus C, Tesfaye D, Jonas E, Scholz AM, Tholen E, Looft C, Wimmers K et al. (2011) Quantitative trait loci analysis for leg weakness related traits in a Duroc Pietrain crossbred population. Genet Sel Evol 43:13.

Li H (2011) A statistical framework for SNP calling, mutation discovery, association mapping and population genetical parameter estimation from sequencing data. Bioinformatics 27:2987-2993.

Li H and Durbin R (2009) Fast and accurate short read alignment with Burrows-Wheeler transform. Bioinformatics 25:1754-1760.

Li H, Handsaker B, Wysoker A, Fennell T, Ruan J, Homer N, Marth G, Abecasis G and Durbin R (2009) The Sequence Alignment/Map format and SAMtools. Bioinformatics 25:2078-2079.

Luo Y, Qiu X, Li H and Zhang Q (2010) Association between the polymorphism in FUT1 gene and the resistance to PWD and $\mathrm{ED}$ in three pig breeds. Asian-Australas J Anim Sci 23:1268-1275.

Ma J, Qi W, Ren D, Duan Y, Qiao R, Guo Y, Yang Z, Li L, Milan D, Ren J and Huang L (2009) A genome scan for quantitative trait loci affecting three ear traits in a White Duroc $\mathrm{x}$ Chinese Erhualian resource population. Anim Genet 40:463-467.

Meijerink E, Fries R, Vögeli P, Masabanda J, Wigger G, Stricker C, Neuenschwander S, Bertschinger HU and Stranzinger G (1997) Two $\alpha(1,2)$ fucosyltransferase genes on porcine Chromosome 6q11 are closely linked to the blood group inhibitor $(S)$ and Escherichia coli $\mathrm{F} 18$ receptor $(E C F 18 R)$ loci. Mamm Genome 8:736-741.

Meijerink E, Neuenschwander S, Fries R, Dinter A, Bertschinger GS and Vögeli P (2000) A DNA polymorphism influencing $\alpha(1,2)$ fucosyltransferase activity of the pig FUT1 enzyme determines susceptibility of small intestinal epithelium to Escherichia coli F18 adhesion. Immunogenetics 52:129-136.

Mracek T, Ding Q, Tzanavari T, Kos K, Pinkney J, Wilding J, Trayhurn P and Bing C (2010) The adipokine zinc- $\alpha 2-$ glycoprotein $(\mathrm{ZAG})$ is downregulated with fat mass expansion in obesity. Clin Endocrinol 72:334-341.
Okonechnikov K, Conesa A and García-Alcalde F (2016) Qualimap 2: Advanced multi-sample quality control for highthroughput sequencing data. Bioinformatics 32:292-294.

Ollivier L (2009) European pig genetic diversity: A minireview. Animal 3:915-924.

Ribani A, Bertolini F, Schiavo G, Scotti E, Utzeri VJ, Dall'Olio S, Trevisi P, Bosi P and Fontanesi L (2017) Next generation semiconductor based sequencing of bitter taste receptor genes in different pig populations and association analysis using a selective DNA pool-seq approach. Anim Genet 48:97-102.

Rothschild M, Jacobson C, Vaske D, Tuggle C, Wang L, Short T, Eckardt G, Sasaki S, Vincent A, McLaren D et al. (1996) The estrogen receptor locus is associated with a major gene influencing litter size in pigs. Proc Natl Acad Sci U S A 93:201-205.

Rothschild M, Messer L, Day A, Wales R, Short T, Southwood O and Plastow G (2000) Investigation of the retinol-binding protein 4 (RBP4) gene as a candidate gene for increased litter size in pigs. Mamm Genome 11:75-77.

Rubin CJ, Megens HJ, Barrio AM, Maqbool K, Sayyab S, Schwochow D, Wang C, Carlborg O, Jern P, Jørgensen CB et al. (2012) Strong signatures of selection in the domestic pig genome. Proc Natl Acad Sci U S A 109:19529-19536.

Russo V, Fontanesi L, Davoli R, Chiofalo L, Liotta L and Zumbo A (2004) Analysis of single necleotide polymorphisms in major and candidate genes for production traits in Nero Siciliano pig breed. Ital J Anim Sci 3:19-29.

Sanseverino W, Hénaff E, Vives C, Pinosio S, Burgos-Paz W, Morgante-Onsins SE, Garcia-Mas J and Casacuberta JM (2015) Transposon insertions, structural variations, and SNPs contribute to the evolution of the melon genome. Mol Biol Evol 32:2760-2774.

Tapio I, Värv S, Bennewitz J, Maleviciute J, Fimland E, Grislis Z, Meuwissen TH, Miceikiene I, Olsaker I, Viinalass H et al. (2006) Prioritization for conservation of northern European cattle breeds based on analysis of microsatellite data. Conserv Biol 20:1768-1779.

Tomás A, Casellas J, Ramírez O, Muñoz G, Noguera J and Sánchez A (2006) High amino acid variation in the intracellular domain of the pig prolactin receptor (PRLR) and its relation to ovulation rate and piglet survival traits. J Anim Sci 84:1991-1998.

van Rens BTTM, Evans GJ and Van Der Lende T (2003) Components of litter size in gilts with different prolactin receptor genotypes. Theriogenology 59:915-926.

Vincent AL, Tuggle CK, Rothschild MF, Evans G, Short TH, Southwood OI and Plastow GS (1998) The prolactin receptor gene is associated with increased litter size in pigs. Swine Research Report, 1997.

Warr A, Robert C, Hume D, Archibald AL, Deeb N and Watson M (2015) Identification of low-confidence regions in the pig reference genome (Sscrofa10.2). Front Genet 6:338.

Wilkinson S, Lu ZH, Megens HJ, Archibald AL, Haley C, Jackson IJ, Groenen MA, Crooijans RP, Ogden R and Wiener P (2013) Signatures of diversifying selection in European pig breeds. PLoS Genet 9:e1009453

Ye K, Schulz MH, Long Q, Apweiler R and Ning Z (2009) Pindel: A pattern growth approach to detect break points of large deletions and medium sized insertions from paired-end short reads. Bioinformatics 25:2865-2871. 
Zhang Y, Wang M, Yu XQ, Ye CR and Zhu JG (2015) Analysis of polymorphisms in the FUT1 and TAP1 genes and their influence on immune performance in Pudong White pigs. Genet Mol Res 14:17193-17203.

Zhao Y,Li N,Xiao L,Cao G,Chen Y,Zhang S,Chen Y,Wu C, Zhang J,Sun S et al. (1998). FSHBsubunitgeneis associated with majorgenecontrolling litter size in commercial pig breeds. Sci China C Life Sci 1(6):664-668.

\section{Internet resources}

Domestic Animal Diversity Information System (DAD-IS), http://dad.fao.org/.

\section{Supplementary material}

The following online material is available for this article:
'Table S1 - SNPs and short INDELs detected by SUPERW on fitness related genes and their classification into categories by SnpEff. Variants classified as high impact and related putative consequences on protein's functionalities. Table S2 - SNPs and short INDELs detected by SUPERW on fitness related genes and their classification into categories by SnpEff. Variants classified as moderate impact on protein function.

Table S3 - SNPs and short INDELs detected by SUPERW on fitness related genes and their classification into categories by SnpEff. Variants classified as low impact on protein function.

Associate Editor: Guilherme Corrêa de Oliveira

License information: This is an open-access article distributed under the terms of the Creative Commons Attribution License (type CC-BY), which permits unrestricted use, distribution and reproduction in any medium, provided the original article is properly cited. 